Published online 03 may 2014

International Journal of Science and Mathematics Education, Springer

DOI- 10.1007/s10763-014-9544-y

Print ISSN: 1571-0068

OnlineISSn 1573-1774

Developing Pre-Service Teachers' Noticing of Students' Understanding of the

\title{
Derivative Concept
}

Gloria Sánchez-Matamoros ${ }^{1}$; Ceneida Fernández ${ }^{2}$; Salvador Llinares ${ }^{2}$

gsanchezmatamoros@us.es, Ceneida.fernandez@ua.es, sllinares@ua.es,

(1)Department of Didactics of Mathematics. University of Seville. Spain

(2) Department of Innovation and Didactic Training. University of Alicante. Spain

Gloria Sánchez-Matamoros,

Universidad de Sevilla.

gsanchezmatamoros@us.es,

Ceneida Fernández,

Universidad de Alicante.

ceneida.fernandez@ua.es,

Salvador Llinares,

Universidad de Alicante.

sllinares@ua.es,

\begin{abstract}
This research study examines the development of the ability of pre-service teachers to notice signs of students' understanding of the derivative concept. It analyses pre-service teachers' interpretations of written solutions to problems involving the derivative concept before and after participating in a teacher training module. The results indicate that the development of this skill is linked to pre-service teachers' progressive understanding of the mathematical elements that students use to solve problems. We have used these results to make some suggestions for teacher training programmes.
\end{abstract}

Key words: professional noticing, knowledge for mathematics teaching, teacher learning, understanding of derivative. 


\section{Developing Pre-Service Teachers' Noticing of Students' Understanding of the Derivative Concept}

\section{INTRODUCTION}

In the last two decades, research on teacher learning has focused on the skill of noticing considered as a component of expert practice. Noticing has been defined in a multitude of ways but the common theme is how teachers process complex classroom events (Jacobs, Lamb \& Philipp 2010; Mason, 2002; van Es \& Sherin, 2008). In initial teacher education contexts, the interest on the development of the noticing skill can be seen as a way to understand how pre-service teachers learn to make sense the mathematics teaching and learning. A particular focus is pre-service teachers' noticing of students' mathematical thinking conceptualized as attending to students' strategies, interpreting students' mathematical understanding, and deciding how to respond on the basis of students' understanding. In this context, we have seen an emphasis on the need for teachers to base their teaching decisions on their students' learning characteristics of mathematical content (Franke \& Kazemi, 2001). This has raised a number of questions about the way in which teachers notice the signs of students' understanding (An \& Wu, 2012; Fernandez, Llinares \& Valls, 2012; Magiera, van den Kieboom \& Moyer, 2013) and about the development of this skill (Bartell, Webel, Bowen \& Dyson, 2013; Fernández, Llinares \& Valls, 2013; Wilson, Mojica \& Confrey, 2013; Spitzer, Phelps, Beyers, Johnson \& Sieminski, 2011). These research studies support the idea that teachers must know how students understand mathematical topics in order to make appropriate teaching decisions.

The different approaches to teachers' knowledge of teaching (Ball, Thames \& Phelps, 2008) state that, in addition to having mathematical knowledge, teachers must have an understanding of how students understand mathematical ideas. In this context, we must 
consider the need to obtain information about how pre-service teachers develop their ability to notice the signs of mathematical understanding when students set out to solve problems. For example, Fernández et al. (2013) studied how pre-service primary school teachers noticed the signs of development of proportional reasoning. The results provided information about the development of this skill. These features were based on the ability of pre-service teachers to differentiate between proportional and non-proportional situations going beyond merely considering the correction of the answer as proof of conceptual understanding. Likewise, Bartell et al. (2013) state that the ability of pre-service teachers to analyse their students' answers has room for improvement. Furthermore, Magiera et al. (2013) note that mathematical knowledge of pre-service teachers plays different roles with regards to the noticing of students' understanding in a clinical interview context and in a context of assessment of written answers.

The results of these research studies suggest that the ability to notice the signs of mathematical understanding by studying a student's answers is a complex skill which, in some cases, can be developed on teacher training programmes. Most of these research studies provide information about primary or secondary school teachers and focus on basic mathematical concepts (equipartitioning, Wilson et al., 2013; proportional reasoning, Fernández et al. 2013; Algebraic reasoning in elementary school, Jacobs, Franke, Carpenter, Levi \& Battey, 2007; algebraic thinking, Magiera et al., 2013; subtraction of decimals, comparison of fractions and multiplication of fractions, Bartell et al., 2013). However, there are few studies that focus on secondary school teachers and concepts of advanced mathematical thinking. Based on the above-mentioned studies, and in a context of secondary school teachers' initial training, our research study provides information about how preservice secondary school teachers learn to notice the signs of students' understanding of the derivative concept. Calculus has proven difficult to teach for teachers, and difficult to learn 
for students, which is why we have provided information about how pre-service teachers develop the ability to notice students' understanding of basic notions of calculus, particularly, of the derivative concept.

\section{Understanding the derivative concept}

Students encounter many difficulties understanding the derivative concept linked to the modes of representation, the relation between the derivative of a function at a point and the global view of the derived function, and the relation between the first and second derivative of a function (Artigue, 1990; Sánchez-Matamoros, García \& Llinares, 2006; SánchezMatamoros, García \& Llinares, 2008).

Students may understand the meanings linked to the derivative concept in analytical and graphical modes, but often they have difficulties linking the two. For example, when students try to sketch the graph of the derived function they have difficulties relating the graph of the function with the analytical expression, and relating the idea of the tangent line with the derived function (Asiala, Cottrill, Dubinsky \& Schwingendorf, 1997; Biza, Christou \& Zachariades, 2008; Ferrini-Mundy \& Graham, 1994). Achieving the relation between the analytical and graphical modes is gradual and depends on some characteristics of the functions, such as the existence of the cusp point (Baker, Cooley \& Trigueros, 2000). Furthermore, some research has shown that the analytical mode dominates the majority of students' thinking because the mathematical definitions are usually analytical (Habre \& Abboud, 2006). With regard to the analytical mode students have difficulties understanding the need for equality of lateral limits when using the concept of the derivative as the limit of the difference quotient (Zandieth, 2000). Regarding the graphical mode, in the study of Nagle, Moore-Russo, Viglietti \& Martin (2013) is considered that the most frequently used conceptualizations for students align with past research findings on the emphasis of the 
secondary mathematics curriculum, supporting the possibility of cultural influences (academic and geographic) on individuals' conceptualizations of slope.

Secondly, students are able to understand what is meant by the global view of the derivative concept (on intervals) and by the derivative concept at a point (at $\mathrm{x}=\mathrm{a}$ ) in different modes of representation (Badillo, Azcárate \& Font, 2011). Finally, students have also difficulties transferring the relationship between the function and the derived function to the relationship between the first and second derivative of a function (Baker et al., 2000; García, Llinares \& Sánchez-Matamoros, 2011)

Taking into account previous research regarding students' understanding of the derivative concept and considering the Spanish curricula, an intended learning trajectory (Clements \& Sarama, 2004) of the derivative concept was described (Figure 1). Limit, continuity and derivability concepts are part of the Spanish curricula. High school students start estimating and measuring on the paper, they continue dealing with numerical aspects (tables, limit of the difference quotient, instantaneous rate of change (IRC) and average rate of change (ARC)) and finally, with the approximation to the slope. The intended learning trajectory describes a hypothetical trajectory in which students refine their initial understanding of the derivative of a function at a point in the analytical-numerical mode to the understanding of the derivative of a function at a point in the graphical mode. Finally, students achieve a more sophisticated understanding about the way in which the first derivative provides information about the behaviour of the function in graphical and analytical modes.
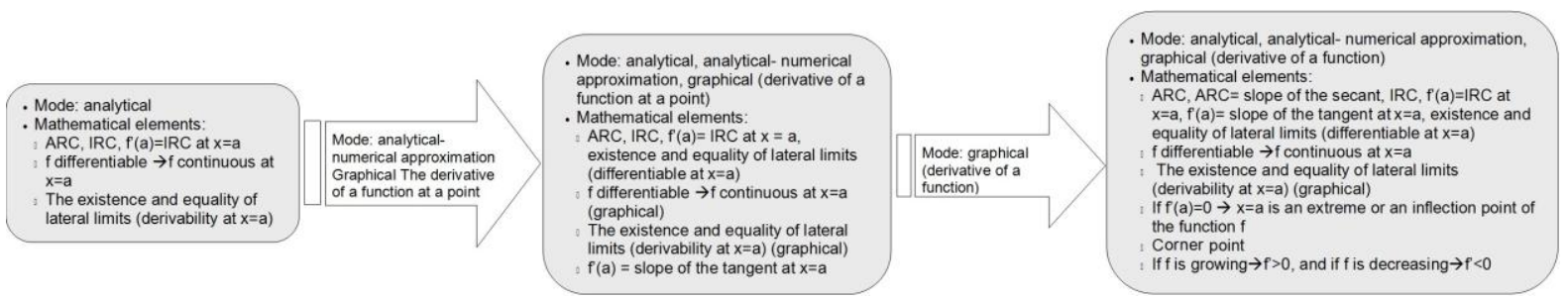

Figure 1. The intended learning trajectory of the derivative concept 
This research study focuses on how we can use the research results regarding the understanding of the derivative concept as a referent to help pre-service teachers to notice the signs of students' understanding. Despite the fact that the development of this skill is part of a teacher's training objectives, we still do not know much about how it is developed.

The objective of this research study is to characterize how pre-service mathematics teachers learn to notice the signs of students' understanding of the derivative concept. In order to do this, we have examined how pre-service teachers show signs of noticing the students' mathematical understanding after participating in a teaching module specifically designed for this purpose. Taking into account the above-mentioned references, we aim to answer the following questions:

$\checkmark$ How do pre-service mathematics teachers recognise students' understanding of the derivative concept after having participated in an ad hoc learning environment?

$\checkmark$ What characterises the development of pre-service mathematics teachers' skill of noticing the signs of students' understanding?

\section{METHOD}

\section{Participants and context}

This research study involved the participation of 8 undergraduate mathematics students enrolled on a course of Didactics of Mathematics for Secondary Education, hereinafter referred to as "pre-service secondary school mathematics teachers" (PMTs). The objective of this course was to support the development of PMTs' ability to view mathematics teaching in a structured way. The design of the activities carried out on this course was based on conjectures about teacher learning taken from the literature review. For example, one of the conjectures was that being able to describe students' answers in detail could help with noticing evidences of students' understanding. 


\section{Design of the teaching module}

The teaching module involved seven sessions of two hours in length (a session per week) (figure 2). Its design was based on the research about students' learning of Calculus and, particularly, the intended learning trajectory involved in understanding the derivative concept (figure 1). The module's objective was to provide the PMTs with information, based on previous research results, about the development of the understanding of the derivative concept in order to support the development of their ability to notice the signs of students' understanding.

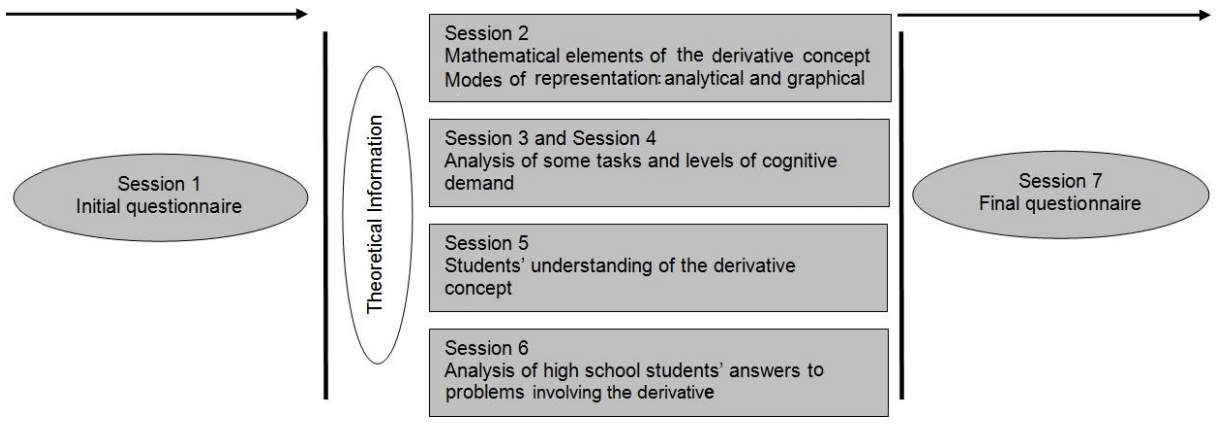

Figure 2. Diagram of the design of the derivative module

In the first and final session the PMTs were asked to complete a questionnaire (which is described later on). In the five remaining sessions, the PMTs were given information about the characteristics of problems related to the derivative concept and about students' understanding of the derivative concept. Particularly, in session 2, they identified the mathematical elements of the derivative concept in different modes of representation in different tasks (rate of change, graphical interpretation of the derivative and difference quotient, equality of lateral limits, the relationship between the derived function and the function). To do this, the PMTs solved the problems of the first questionnaire and identified the mathematical elements used to solve them. In sessions 3 and 4, the PMTs had to classify a group of problems involving the derivative concept and justify their classification by taking into account the mathematical elements that needed to solve them. Finally, in sessions 5 and 
6, the PMTs were given information about the way in which students learn the derivative concept, the difficulties they encounter and the role of the different modes of representation. During these sessions, the PMTs worked in pairs to analyse answers of high school students (16-18 years of age) to problems involving the derivative and were asked to identify and discuss what they thought were signs of student understanding. The PMTs solved in pairs the suggested tasks of the sessions and, at the end of each session, participated in a group discussion about the ideas they had noticed when solving the tasks.

\section{The questionnaires}

The questionnaires were designed by taking into account the characteristics of the intended learning trajectory involved in understanding the derivative, summarised from previous research studies (figure 1). In particular, we considered an intended learning trajectory of the derivative concept of a function at a point (figure 4) and an intended learning trajectory of the derived function (figure 6). Each questionnaire consisted of three high school student answers to various problems involving the derivative and, excerpts from an interview containing the reasoning used by the high school student to solve the problem. The aim of adding excerpts from students' interviews was to give more insight into their responses and to provide more information about their understanding of derivative. Students' responses in the questionnaires real and were chosen from a previous study (Sánchez-matamoros, García \& Llinares, 2006; García, Llinares, \& Sánchez-matamoros, 2011). PMTs had to answer the next two questions for each one of the high school students' responses:

1. Describe how student $X$ has solved each of the problems, stating the elements of the derivative concept he/she has used and whether the chosen procedure is appropriate and why. 
2. From the descriptions of how the student has set out to solve the three problems, is it possible to identify any characteristics with regards to how student $X$ understands the derivative concept? Problems and high school students' answers of the initial questionnaire

The first questionnaire presented the answers of 3 high school students to 3 problems (problems and a student's answers are shown in figure 3).

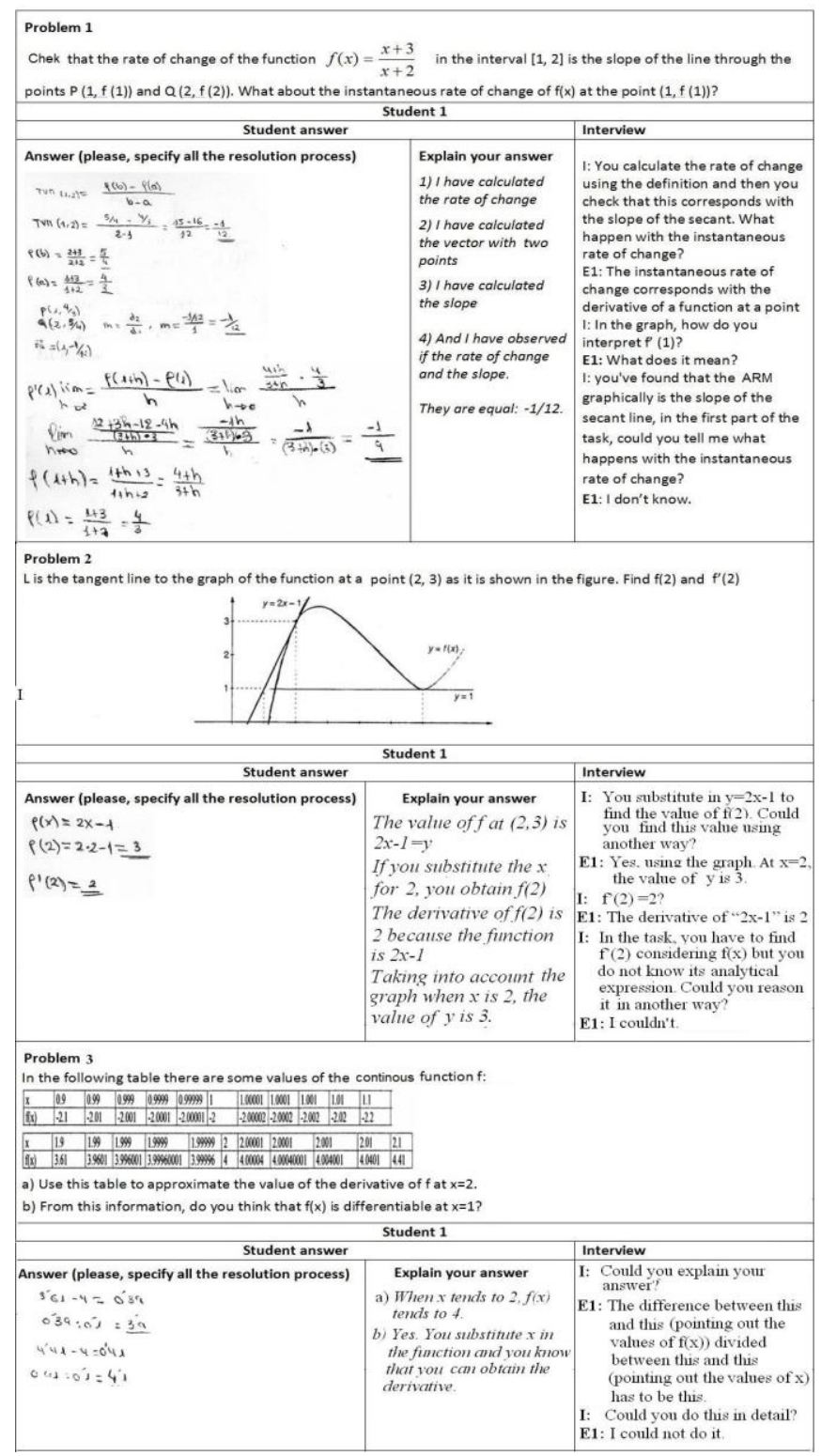

Figure 3. Problems of the first questionnaire: student 1's answers to the three problems (P1, $P 2$ and $P 3)$ 
Problem 1 provides the analytical mode of a function $\mathrm{f}$ and asks the student to check that the Average Rate of Change (ARC) in the interval $[1,2]$ is the slope of the secant line through the points of axis $x=1$ and $x=2$ and to calculate the Instantaneous Rate of Change (IRC) at $x=$ 1. This problem asks the student to reproduce the formula for calculating the ARC, link it with its graphical meaning and the meaning of the IRC through the interview.

Problem 2 presents the graph of a function $f$, the graph of the slope of the tangent line to $f$ at $(2,3)$ and the equation of the tangent line. The problem asks the student to find the value of $\mathrm{f}$ and $\mathrm{f}^{\prime}$ at point $\mathrm{x}=2$. The aim of this problem is to use the graphical interpretation of the derivative (the derivative of the function at a point is the slope of the tangent line to the graph of the function at that point).

Problem 3 provides a table with information on the behaviour of a continuous function $f$ at two points, $\mathrm{x}=1$ and $\mathrm{x}=2$. The problem asks the student to provide information about $f^{\prime}$ at those points. The aim of the problem is to use the derivative as a numerical approximation through the limits of the difference quotient. The existence of the derivative at these points requires the existence and equality of the lateral limits of the difference quotient. The solution to the problem is based on the value of the derivative at a point as the limits of the difference quotient.

High school students' answers to the problems included in the questionnaire refer to an intended learning trajectory of the derivative of a function at a point (figure 4). Each student has a different level of understanding of the derivative of a function at a point depending on the moment of the intended learning trajectory that is situated. In this questionnaire, student 1 used elements of the derivative of a function at a point in the analytical mode only (figure 4). Student 3 was able to use the numerical approximation of the derivative of a function at a point through analytical expression as a limit of the difference quotient, but the student had difficulties linking the analytical and graphical modes. Finally, student 2 used all of the 
elements of the derivative of a function at a point in all of the modes of representation, linking them, when necessary, to the solutions to the problems.

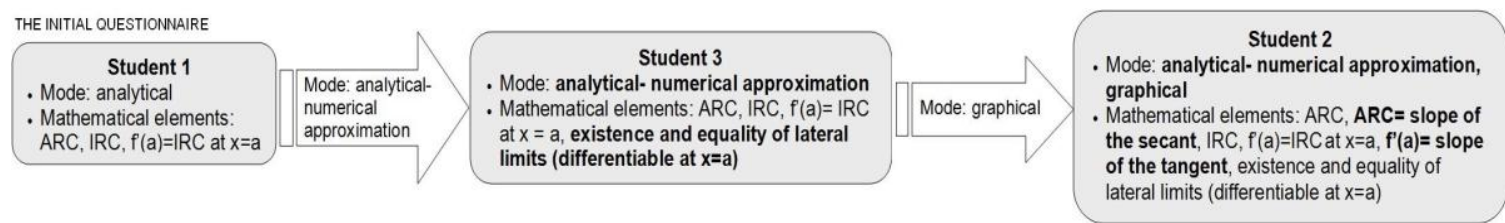

Figure 4. Intended learning trajectory of the concept of the "derivative of a function at a point" used for the design of the initial questionnaire

Problems and high school students' answers of the final questionnaire

The final questionnaire contained the answers of 3 students to 2 problems related to the derived function (figure 5).

Problem 1 presents the analytical expression of a piecewise function depending on two parameters and asks the students to provide the values of the parameters so that the function is differentiable at $\mathrm{x}=1$. The solution to this problem is based on the coordination of the elements

- $\quad \mathrm{f}$ is differentiable $\rightarrow \mathrm{f}$ is continuous, and

- the existence and equality of the lateral limits of $\mathrm{f}^{\prime}$ at $\mathrm{x}=1 \rightarrow \mathrm{f}^{\prime}$ ' is continuous at $\mathrm{x}=1$

Problem 2 presents the graphic of a piecewise function formed by branches of parabolas. It asks the students to obtain the values of $\mathrm{f}^{\prime}$ for certain points and to sketch the graph of the derived function.

In order to solve section (a), students must use the mathematical elements relative to the maximums and minimums and the conditions of differentiability of $\mathrm{f}$ :

- $\quad \mathrm{f}^{\prime}(\mathrm{a})=$ slope of the tangent line to $\mathrm{f}$ at $\mathrm{x}=\mathrm{a}$ 
- $\quad \mathrm{f}$ is differentiable at $\mathrm{x}=\mathrm{a} \rightarrow \mathrm{f}$ is continuous at $\mathrm{x}=\mathrm{a}$ (negation)

$-\quad \mathrm{x}=$ a extreme of the function $\mathrm{f}$ (parabola) $\rightarrow \mathrm{f}^{\prime}(\mathrm{a})=0$

- if $\mathrm{f}$ is increasing $\rightarrow \mathrm{f}^{\prime}>0$, and if $\mathrm{f}$ is decreasing $\rightarrow \mathrm{f}^{\prime}<0$

- the existence and equality of lateral limits of the difference quotient (as a process, approximation through the tables of values) for $f^{\prime}(a)$ to exist.

- corner point: if $f$ is continuous in $(a, b)$, differentiable in $(a, b)-\{c\}$, and the lateral derivatives at $\mathrm{x}=\mathrm{c}$ are not equal and are real number, then $\mathrm{x}=\mathrm{c}$ is a corner point.

In order to solve section b (problem 2), students needed to use the coordination of the previous mathematical elements, is that, to sketch the graph of $\mathrm{f}^{\prime}$, students have to use the different mathematical elements of section a) and consider the implication " $\mathrm{f}$ is a parabola then $\mathrm{f}^{\prime}$ is a straight line" 


\begin{tabular}{|c|c|c|}
\hline \multicolumn{3}{|c|}{$\begin{array}{l}\text { Problem } 1 \\
\text { Let } f(x)=\left\{\begin{array}{cc}2 x^{3}+2 x+a & x<1 \\
b x^{2}+1 & x \geq 1\end{array} \text { Find } \mathrm{a} \text { and } \mathrm{b} \text { such that } \mathrm{f} \text { is differentiable at } \mathrm{x}=1 \text {. }\right.\end{array}$} \\
\hline \multicolumn{3}{|c|}{ Student 2} \\
\hline Student answer & & Interview \\
\hline 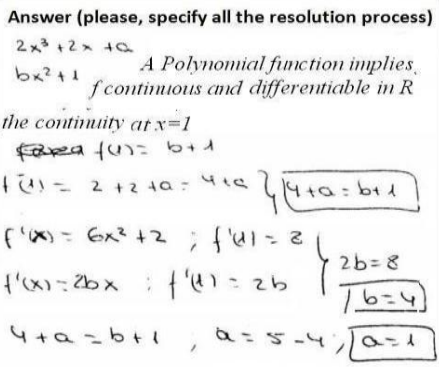 & $\begin{array}{l}\text { Explain your answer } \\
\text { Firstly, I study the continuity and } \\
\text { differentiability of the two functions } \\
\text { I study the contimity of the two } \\
\text { functions at } x=1 \\
\text { I have done the derivative of each } \\
\text { finction and then I have obtained } \\
\text { the derivativeat } x=1 \\
\text { If } b=4 \text { and a }=1 \text {, the two functions } \\
\text { will not have any problem at } x=1 \\
\text { where the functions could have } \\
\text { problems of differentiability. }\end{array}$ & $\begin{array}{l}\text { I: You say that firstly you study the continuity, } \\
\text { why? } \\
\text { 22: Because } f \text { is differentiable if } \mathrm{f} \text { is continuous } \\
\text { If } \mathrm{f} \text { is not continuous, } \mathrm{f} \text { could not be } \\
\text { differentiable. }\end{array}$ \\
\hline \multicolumn{3}{|c|}{$\begin{array}{l}\text { Problem } 2 \\
\text { Given the graph of the function } f \text {, formed by the branches of the parabolas } \\
\text { a) Find the values of } f^{\prime}(3), f^{\prime}(7), f^{\prime}(10), f^{\prime}(14) \text { and } f^{\prime}(15) \text {. Explain how you obtain them, } \\
\text { b) Sketch the graph of } f^{\prime} \text {. Explain how you obtain it. }\end{array}$} \\
\hline \multicolumn{3}{|c|}{$\begin{array}{ll} & \text { Student } 2 \\
\end{array}$} \\
\hline Student answer & & Interview \\
\hline $\begin{array}{l}\text { Answer (please, specify all the resolution process) } \\
f^{\prime}(3)=\frac{3}{2} \\
f^{\prime}(7)=0 \\
f^{\prime}(10)=\text { No tiene deuciedo } \\
f^{\prime}(14)=\text { wo liene }\end{array}$ & $\begin{array}{l}\text { Explain your answer } \\
\text { As the derivative is the slope, I find the } \\
\text { value of the slopes. } \\
\text { Becanise it changes the convexity or..., } \\
\text { I do not know it. } \\
\text { Because fis not contimious at } x=10 \\
\text { Becculse it is a peak }\end{array}$ & 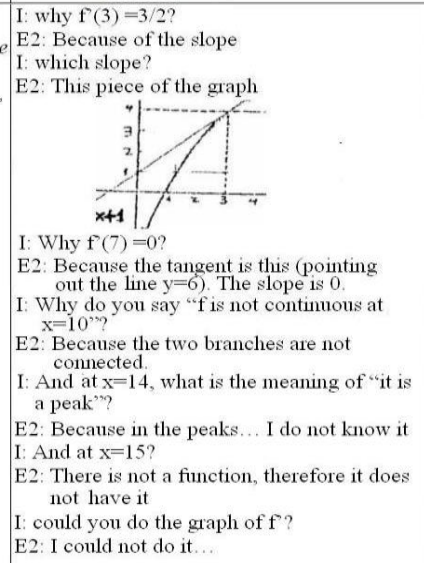 \\
\hline
\end{tabular}

Figure 5. Problems of the final questionnaire: Student 2's answer to the two problems

The students' answers to these problems were chosen by taking into account the intended learning trajectory involved in understanding the derived function (figure 6). Each student showed a different level of understanding of the derivative function. In this questionnaire, student 1 used elements of the derived function in the analytical mode, student 2 used elements of the derivative in the analytical and graphical modes but only at certain points (derivative of the function at a point) while student 3 used all of the elements of the derivative in the different modes of representation. 


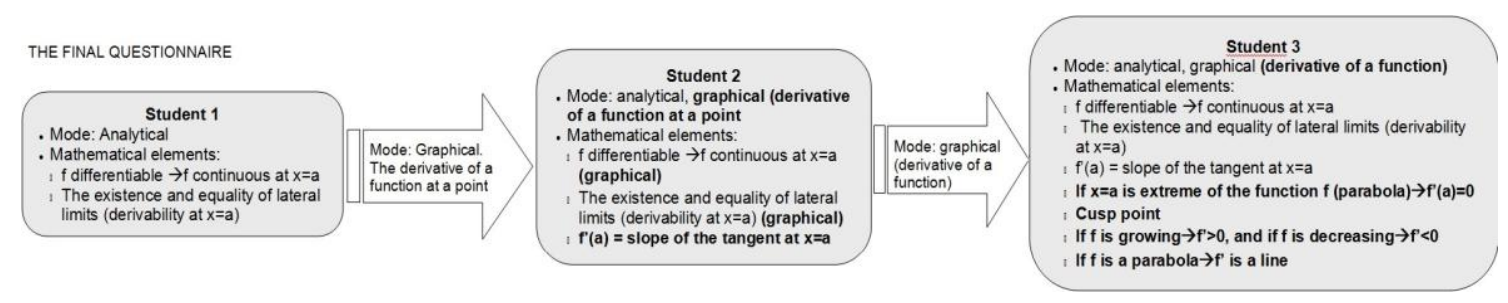

Figure 6.Intended learning trajectory of the "concept of derived function" used to design the final questionnaire

\section{Data analysis}

The two questionnaires were designed to assess how the PMTs notice the signs of students' understanding of the derivative concept, before and after the teaching module. In order to perform the analysis, we focused on how the PMTs described the student's answers using the mathematical elements and the modes of representation (Question 1) and how they explained that these answers were signs of students' understanding (Question 2). In this last question, we analysed if PMTs used the mathematical elements identified previously (in Question 1) with meaning to provide information about students' understanding.

We have included below an example of how we performed the analysis and in what way we integrated our inferences about the ability of the PMTs to notice the signs of the students' understanding.

With regards to the understanding of student 1 (figure 3), the pre-service teacher MV wrote: "I don't think the student understands the derivative concept at a point, given that he/she only applies certain formulas depending on the problem".

With this answer, we cannot infer whether MV has identified the characteristics of student 1's understanding given that he/she does not mention the analytical mode of representation or the problem's specific mathematical elements - average rate of change (ARC), instantaneous rate of change (IRC) and the fact that the derivative of the function at $\mathrm{x}=\mathrm{a}$ coincides with the instantaneous rate of change at $\mathrm{x}=\mathrm{a}$. In this case, MV's answer to the first question provides 
additional information about the way in which he/she identified the characteristics of the problems: "The student solved the problem well in parts of the exercise, using a function at a point, the ARC formula, the formula for the slope of the (secant) line and the definition of the derivative to calculate the IRC",

This answer indicates that MV identified and used the mathematical elements used by the student to solve the problem in order to support his/her reasoning about the student's understanding of the derivative concept.

By applying a constant comparative method (Strauss \& Corbin, 1994) to the PMTs' answers to the two questions, we were able to identify certain characteristics in their answers (categories). In order to ensure the validity and reliability of the analysis, a small data sample was first analysed by a group of four researchers, who discussed the codes and links between the evidence and the codes used to create the different categories. Once the researchers had reached an agreement, new data samples were added in order to review the categories system initially created. We then compared the analysis of both questionnaires with the objective of creating descriptors of the development of the ability to notice the signs of students' understanding. This procedure has enabled us to identify three levels of development of the ability to notice students' understanding, which will be described in the results section.

- Low level: when the PMTs view the students' understanding as "all or nothing".

- Medium level: when the PMTs identify some characteristics of the students' understanding with regards to some mathematical elements.

- High level: when the PMTs identify the different characteristics of the students' understanding from a detailed description of the students' answers.

\section{RESULTS}


The analysis of both questionnaires showed changes in the ability of the PMTs to notice the signs of the students' understanding (Table 1) after participating in the teaching module. In the first questionnaire, all of the PMTs made general descriptions of the students' answers, describing their understanding as "understands" vs. "does not understand". However, in the final questionnaire, six of the PMTs gave more detailed descriptions which enabled them to identify a larger number of differences in the way in which the students seemed to understand the derivative concept.

Table 1. PMTs levels of noticing the signs of students' understanding after and before the teaching module

\begin{tabular}{|c|c|c|c|}
\hline & & First questionnaire & Final questionnaire \\
\hline \multirow{3}{*}{ 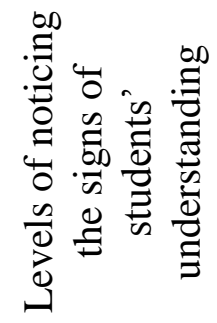 } & Low & 8 & 2 \\
\hline & Medium & 0 & 4 \\
\hline & High & 0 & 2 \\
\hline
\end{tabular}

\section{Prior to the teaching module (first questionnaire)}

In the first questionnaire, the eight PMTs made general descriptions of the students' answers and described their understanding as "all or nothing", using expressions such as "he/she does not understand" and "he/she does not apply the definition". Thus, the PMTs did not notice that the three students showed different levels of understanding of the derivative of a function at a point. For example, the pre-service teacher AAC made the following remark about student 1 (figure 4):

The student uses the formulas for calculating the ARC (Average Rate of Change) and IRC (Instantaneous Rate of Change) when the problem clearly states that this is what he/she needs to use. However, when the problem is presented as a graphical representation or in a table, the student does not apply the derivative concept at a point. 
AAC thus provided general descriptions of the way in which the students solved the problems and made his/her assumption about their understanding based on this description. This is how AAC identified that student 1 used the mathematical elements of ARC and IRC in analytical mode and mentioned the difficulty he/she encounters with the graphical meaning in graphical mode and the numerical approximations using tables. However, AAC did not identify the role of the existence and equality of the lateral limits in the numerical approximation, which made it difficult for him/her to recognise the different responses of the three students. The solution to problem 3 requires the use of the derivative concept as a limit of the difference quotient in a context of numerical approximation. In this case, the student needs to consider the existence and equality of the lateral limits (as a process of approximation using the tables of values) in order for the derivative of the function at $\mathrm{x}=\mathrm{a}$, f'(a) to exist.

Despite the fact that student 2 did take this into account when using the ARC for points $\mathrm{x}=2$ and $\mathrm{x}=1$, the pre-service teacher AAC did not differentiate the responses of students 1 and 2 in these situations, which prevented him/her from correctly interpreting their different levels of understanding.

The student understands the derivative concept at a point in the graphical mode. However, when the problem is presented in the form of a table, the student uses the ARC instead of using the derivative formula at a point or the IRC.

Likewise, with regards to the response of student 3 in the numerical approximation through tables of values, AAC stated that: "The student does not understand the derivative concept at a point in graphical mode or with a table of values. He/she only applies the concept correctly when asked to do so, such as in problem 1". 
These general answers are an example of how the PMTs described the students' answers in the first questionnaire, which made it difficult for them to identify differences between students' answers. Thus, prior to beginning the teaching module, the PMTs tended to ignore the importance of certain differences with regards to the way in which the students solved the problems and which could provide additional information about their level of understanding. In other words, the way in which they described the students' answers limited their ability to recognise the students' different levels of understanding.

\section{After the teaching module (final questionnaire)}

After participating in the teaching module, six PMTs were able to recognise more differences among the students' answers. Two of the six PMTs described and interpreted the students' answers based on a large number of mathematical elements and modes of representation in order to recognise the different levels of understanding. Both of these PMTs recognised that student 1's answers reflected his difficulties in using the derivative in graphical mode and that student 2 understood and used, when necessary, the mathematical elements in analytical mode and graphical mode at a point (derivative of a function at a point) but encountered difficulties in using the graphical meaning (derived function) in a global-view (on intervals). Finally, these two PMTs were able to identify that student 3 did not encounter any difficulties in using the different mathematical elements of the derived function in the different modes of representation.

However, four of the six PMTs only identified certain characteristics of the students' understanding of the derivative concept, despite the fact that they described the differences in their responses. This was due to these PMTs not recognising the importance of identifying the different ways in which the students solved the problems relating to the behaviour of the function at the corner point $\mathrm{x}=14$ (problem 2) in order to obtain information about their understanding of the derivative concept. In this case, as it is a corner point requires that the 
student establishes links between the global and point approximations. In other words, it is necessary to take into account both the behaviour of the function in intervals and the behaviour of the function at a point (Baker et al., 2000). Thus, the fact that the PMTs did not recognise the information which could be taken from the way in which the students solved this problem prevented them from interpreting student 3's answer correctly and from noticing the difference with the other two students.

The following sections will present the characteristics of the ability to notice the signs of understanding the derivative concept after participating in the teaching module. The examples we have chosen are representative of the way of proceeding of the PMTs who share the same level of development of the ability to notice.

\section{Levels of development of the ability to notice the signs of understanding}

\section{Low level}

Upon completion of the module, two PMTs continued to provide general descriptions of the students' answers, which made it difficult for them to recognise the differences in their understanding. These PMTs identified the different responses of the students in the graphical and analytical mode, but they did not include additional information about the students' responses from the way in which they solved the problems relating to the behaviour of the function at given points, such as discontinuity points or the corner point. Identifying the students' different responses in these points would have helped them to recognize their different levels of understanding.

For example, ABPG provided a general description of the students' answers. When describing student 1's answer (figure 7), he/she stated that "the student understands the derivative concept in analytical mode but we assume that he does not understand the graphical mode given that he has not answered the question". 


\begin{tabular}{|c|c|c|}
\hline \multicolumn{3}{|c|}{$\begin{array}{l}\text { Problem } 1 \\
\text { Let } f(x)=\left\{\begin{array}{cc}2 x^{3}+2 x+a & x<1 \\
b x^{2}+1 & x \geq 1\end{array} \text { Find } \mathrm{a} \text { and } \mathrm{b} \text { such that } \mathrm{f} \text { is differentiable at } \mathrm{x}=1 \text {. }\right.\end{array}$} \\
\hline \multicolumn{3}{|c|}{ Student 1} \\
\hline Student answer & & Interview \\
\hline 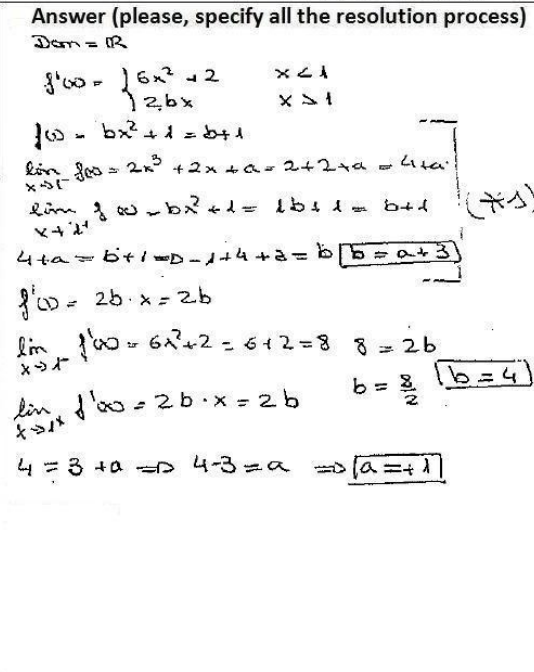 & 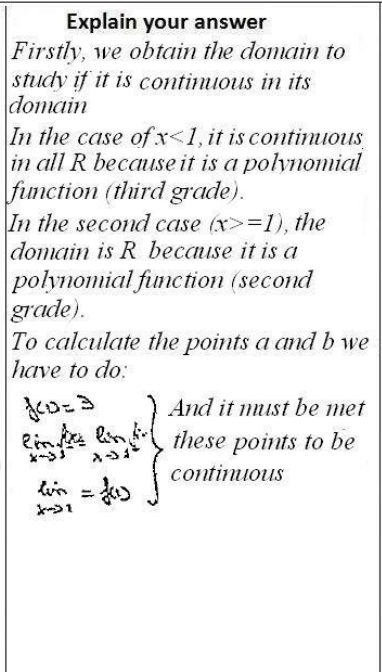 & $\begin{array}{l}\text { I: could you explain how do you solve } \\
\text { the task? } \\
\text { E1: I obtain the domain and then, with the } \\
\text { first function I obtain the points in } \mathrm{f} \text {, } \\
\text { in f and then I calculate the lateral } \\
\text { limits. After, I obtain } \mathrm{f} \text { ' and then I do the } \\
\text { same as f. } \\
\text { I: Here, why do you write the lateral limits } \\
\text { at x=1? } \\
\text { E1: I refers to the continuity } \\
\text { I: The lateral limits of...? } \\
\text { E1: f(1) must exist so the lateral limits have to } \\
\text { be equal } \\
\text { I: Then, the laterals limits are referred to f } \\
\text { E1: Yes, I forgot to write this } \\
\text { I: Why do you study the continuity? } \\
\text { E1: Because if it is continuous, it is } \\
\text { differentiable } \\
\text { I: You study the differentiability calculating } \\
\text { f' through the rules of the derivative, could } \\
\text { you do this through the definition of the } \\
\text { derivative? } \\
\text { E1: I could not do it. }\end{array}$ \\
\hline \multicolumn{3}{|c|}{$\begin{array}{l}\text { Problem } 2 \\
\text { Given the graph of the function } f \text {, formed by the branches of the parabolas } \\
\text { a) Find the values of } f^{\prime}(3), f^{\prime}(7), f^{\prime}(10), f^{\prime}(14) \text { and } f^{\prime}(15) \text {. Explain how you obtain them. } \\
\text { b) Sketch the graph of } f^{\prime} \text {. Explain how you obtain it. }\end{array}$} \\
\hline & Student 1 & \\
\hline Student answer & & Interview \\
\hline Answer (please, specify all the resolution process) & Explain your answer & $\begin{array}{l}\text { I: could you solve this problem? } \\
\text { E1: No, I couldn't } \\
\text { I: In section b) you have to make the graph } \\
\text { of } \mathrm{f} \text { '. Could you do this if you know that } \\
\text { f have three branches that are parabolas? } \\
\text { E1: It must be... a parabola } \\
\text { I: why? } \\
\text { E1:... }\end{array}$ \\
\hline
\end{tabular}

Figure 7- Final questionnaire: Student 1's answers to both problems

In his/her answer, the PMT used the implication "continuity does not imply differentiability" but omitted elements of the graphical mode: "first, the student calculates the derivative of the function without using the definition... (the PMT describes the solution given by the student) ... the procedure is correct, although we must emphasise again that continuity does not imply differentiability". This description of the solution to the problem means that ABPG was not able to recognise certain characteristics of the understanding of the derivative, as can be seen in ABPG's remarks about student 2's answers: 
the student understands the derivative concept in analytical mode but not in graphical mode. He/she has problems when deciding whether the derivative at $x_{0}$ is zero or does not exist, when giving the correct graphical interpretation and when using the existence of maximums and minimums for calculating the derivative at the given point.

In this answer, ABPG focused on the relationship between the graphical and analytical meaning of the derivative concept. ABPG interpreted the student's understanding based on his/her use of the conditions of existence of the derivative at the points in which the function is continuous or has a jump and at the points in which the derivative does not exist. In this case, ABPG described the students' answers without using all of the mathematical elements that needed to be used in order to solve the problem, thereby giving a general description of the answers. As a result, ABPG was not able to identify the difference between student 2 and 3 (figure 8):

in the first exercise, which is analytical, the student shows an adequate understanding of the derivative concept... the problems arise when it comes to the graphical exercises, which is when the student shows signs of doubt and confusion between $f$ and $f^{\prime} . .$.

Although ABPG noticed the student's difference in their responses in the graphical and analytical mode, he/she did not correctly interpret the links the student establishes in graphical mode between the function and its derivative ( $f$ and $f^{\prime}$ ).

\section{Medium level}

Upon completion of the module, four PMTs were placed in the medium level with regards to their development of the ability to identify and interpret the students' understanding. These PMTs identified the relevant aspects of the responses of students 1 and 2 (figures 5 and 7) but did not identify the different responses of the students with regards to the corner points (problem 2), which influenced their interpretation of student 3's understanding (figure 8). 
For example, ARP described student 1's understanding (figure 7) by mentioning the relationship between continuity and differentiability of the function in analytical (but not graphic) mode:

the student understands how a function needs to behave in order to be differentiable at a point... On the other hand... the student is not aware that the derivative of the function at that point coincides with the slope of the tangent line at that point....

This more detailed description of the students' answers enabled this PMT to identify what each of the problems required and to deduce a greater amount of information about the students' understanding from their answers.

\begin{tabular}{|c|c|c|}
\hline \multicolumn{3}{|l|}{ Problem 1} \\
\hline \multicolumn{3}{|c|}{ Student 3} \\
\hline \multicolumn{2}{|l|}{ Student answer } & Interview \\
\hline 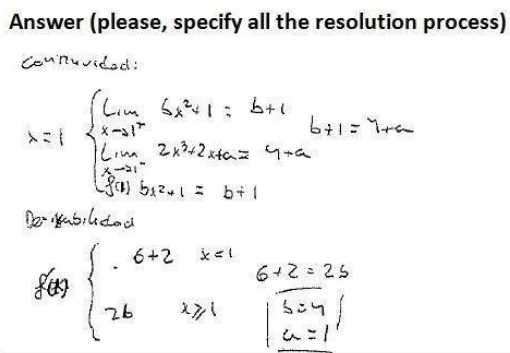 & $\begin{array}{l}\text { Explain your answer } \\
\text { If } f(x) \text { has to be } \\
\text { differentiable at } x=1 \text {, } \\
f(x) \text { has to be } \\
\text { continuous. } \\
\text { We equate the lateral } \\
\text { limits }\end{array}$ & $\begin{array}{l}\text { I: you start the task calculating the continuity, why? } \\
\text { E3: Because if } f(x) \text { has to be differentiable, } f(x) \\
\text { has to be continuous } \\
\text { I: You calculate } f^{\prime} \text { through the derivative rules, could } \\
\text { you obtain } f^{\prime} \text { using another method? } \\
\text { E3: Yes. It's faster. } \\
\text { I: How could vou calculate this using another } \\
\text { method? } \\
\text { E3: With the next expression } f^{\prime}(a)=\lim _{x \rightarrow a} \frac{f(x)-f(a)}{x-a} \\
\text { That is the derivative of a function at a point }\end{array}$ \\
\hline \multicolumn{3}{|c|}{$\begin{array}{l}\text { Problem } 2 \\
\text { Given the graph of the function } f \text {, formed by the branches of the parabolas } \\
\text { a) Find the values of } f^{\prime}(3), f^{\prime}(7), f^{\prime}(10), f^{\prime}(14) \text { and } f^{\prime}(15) \text {. Explain how you obtain them. } \\
\text { b) Sketch the graph of } f^{\prime} \text {. Explain how you obtain it. }\end{array}$} \\
\hline \multicolumn{3}{|c|}{\begin{tabular}{|c|} 
Student 3 \\
\end{tabular}} \\
\hline Student answer & & Interview \\
\hline 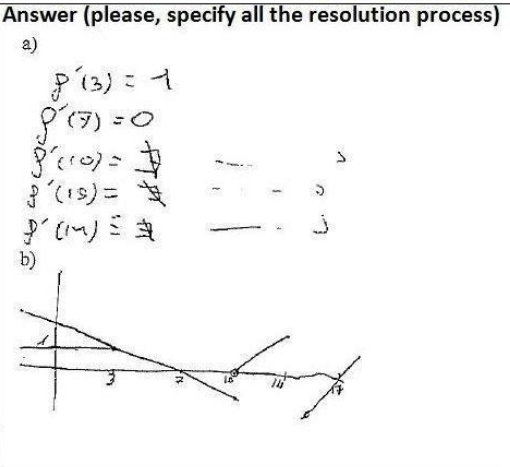 & $\begin{array}{l}\text { Explain your answer } \\
\text { The value of the slope is } 1 . \\
\text { It is a maximum } \\
\text { The function is not } \\
\text { continuous }\end{array}$ & $\begin{array}{l}\text { I: In part a) vou sav that } f^{\prime}(3)=1 \text { because it is the value of } \\
\text { the slope. Could vou explain it? } \\
\text { E3: Because the derivative of the function is the slope of } \\
\text { the tangent line } \\
\text { I: and } f^{\prime}(7) \text { ? } \\
\text { E3: } 0 \text {, because it is a maximum and because the tangent is } \\
\text { parallel to axis } X \text {. This is why the value is } 0 \text {. } \\
\text { I: You sav that the function is not continuous at } x=10 \text {. } \\
\text { Could you explain it? } \\
\text { E3: The lateral limits of } f \text { do not coincide } \\
\text { I: and } f^{\prime}(14) \text { ? } \\
\text { E3: B the left side, the lateral derivative is positive and, by } \\
\text { the right side the lateral derivative is negative (made a } \\
\text { drawing) } \\
\text { I: Could vou explain how do you make the graph of } f^{\prime} \text { ? } \\
\text { E3: When the slope is positive the graph is over axis OX, this } \\
\text { is until } x=7 \text {. From this noint the slope is negative until } \\
x=10 \text {. At } x=10 \text { the function increases until } x=14 \text { that it } \\
\text { starts to decrease again (the value of the slope is ditterent). }\end{array}$ \\
\hline
\end{tabular}

Figure 8: Final questionnaire: Student 3 's answer to the two problems 
In the same way, ARP described student 2's understanding (figure 5) by identifying that he/she used the elements in the analytical and graphical mode at a point but that he/she encountered problems with the derived function. This allowed ARP to differentiate between the responses of students 1 and 2, stating that:

he/she understands the concepts relating to the derivative at a point... the relationship between the slope of the tangent line at a point and the differentiability of the function at that point, the relationship between continuity and differentiability of a function. The student still needs to understand and identify the inflection points and what happens in them as well as the relationship between increase and decrease in the behaviour of the derivative in that interval.

However, ARP did not identify the information from the existence of the corner point (problem 2) as he/she confused it with an inflection point: "the student does not take the inflection point $(x=14)$ as such and says that the derivative does not exist (error)". In addition, ARP did not take into account the extract of student 3's interview, which accompanies the student's solution to problem 2. During this interview, student 3 is asked whether the derivative at $\mathrm{x}=14$ exists, to which he/she replies: "it does not exist given that the lateral derivative is positive to the left and negative to the right". This description influences ARP's interpretation of student 3's understanding (figure 8): “it seems that he/she understands all of the concepts of differentiability. With the exception of the inflection point... the student applies the rest of the data correctly".

\section{High level}

Two PMTs identified the characteristics of the different levels of understanding of the derived function of the 3 students. The identification and interpretation of these characteristics is based on a more detailed explanation of the mathematical elements used to 
solve the problems. In particular, they recognised the relevance of the students' responses with regards to the coordination of the graphical and analytical modes, the role played by the existence and equality of the lateral limits in the relationship between continuity and differentiability, and how the students managed the information regarding the corner points and the minimums and maximums in order to determine the behaviour of the function.

For example, AAC identified that student 1 (figure 7) used the mathematical elements in the analytical mode (problem 1) but that he/she encountered difficulties in the graphic interpretation of the derivative (problem 2).

In the analytical mode exercise, student 1 links the concepts of continuity and differentiability, at $x=1$, to check whether it is differentiable... The student does not understand the connection between the graphical and analytical mode, given that he/she does not link the graph and the formula... Thus, when the student is presented with an analytical problem, he/she knows what he/she has to do. However, when the problem is in graphical mode he/she requires a greater understanding... He/she is not capable of solving it.

With regards to student 2 (figure 5), AAC identified that he/she used the elements in graphical mode in the derivative of a function at a point but not in the derived function: "the student has a geometrical understanding of some concepts (derivatives at maximum points, discontinuity points...) but does not understand the graphical relationship between $f$ and $f$ '. Analytically, the student does not have a clear understanding of the derivative concept..." This interpretation is based on AAC's previous identification of the implication in the analytical mode: "f is differentiable $\rightarrow$ continuous" (and its counter-reciprocal relationship), "not continuous $\rightarrow$ not differentiable". Finally, AAC described in detail the solution provided by student 3 (figure 8 ) to the two problems and interpreted his/her understanding by identifying the mathematical elements he/she used to solve the problems. 
Analytically, the student understands the procedure and the derivative concept... He/she can also identify these concepts geometrically. The student can generally work out $f$ from $f^{\prime}$. Overall, he/she has a good understanding of the derivative concept". "Identify the following: A derivative at a point as a limit of the difference quotient (interview), the existence and equality of the lateral limits of the difference quotient so that $f$ is differentiable, $f$ is differentiable $\rightarrow f$ is continuous, a derivative at a point is the slope of the tangent line in the curve at that point, $f$ is not continuous at a point $\rightarrow f$ is not differentiable at that point, $f$ has a maximum point at $x=a \rightarrow f^{\prime}(a)=0$, if $f$ is increasing in $(a, b) \rightarrow f^{\prime}>0$ in $(a, b)$, if $f$ is decreasing in $(a, b) \rightarrow f^{\prime}<0$ in $(a, b)$.

\section{DISCUSSION}

This research study falls within the research programmes that focus on teachers' learning with the objective of characterising the development of the ability to "notice the signs of students' mathematical understanding". Our focus is on how PMTs come to recognise different levels of student understanding of the derivative concept. The results show changes in the way in which PMTs recognise the signs of students' understanding of the derivative concept after the course. These changes are linked to the PMTs' recognition of the mathematical elements used by the students to solve the problems. Thus, the detailed descriptions of the students' answers given by the PMTs provided them with a means through which to explain their responses and make more informed assumptions of their understanding. These changes allow us to generate descriptors of the development of this skill.

\section{The development of the ability to "notice students' understanding"}

The analysis of the first and final questionnaires has enabled us to characterise the development of this skill in three levels: low, medium and high. The development of the 
ability to notice the students' understanding of the derivative concept can be understood as a transition from descriptions and comparisons containing little detail about the students' answers to more detailed descriptions which enabled the PMTs to make more informed assumptions about the students' understanding (figure 9).

The transition from one level to the next is linked to the way in which the PMTs identified as relevant the relationships between the mathematical elements which the students used to solve the problems. For example:

- The relationship between the limit of the difference quotient and the meaning of the derivative as a slope of the tangent line

- The relationship between the differentiability of the function and its continuity, and

- The way in which the PMTs used the information obtained from the function or the derived function at the inflection points and the corner point (understood as the way of interpreting the behaviour of the derived function in order to make assumptions about the behaviour of the function).

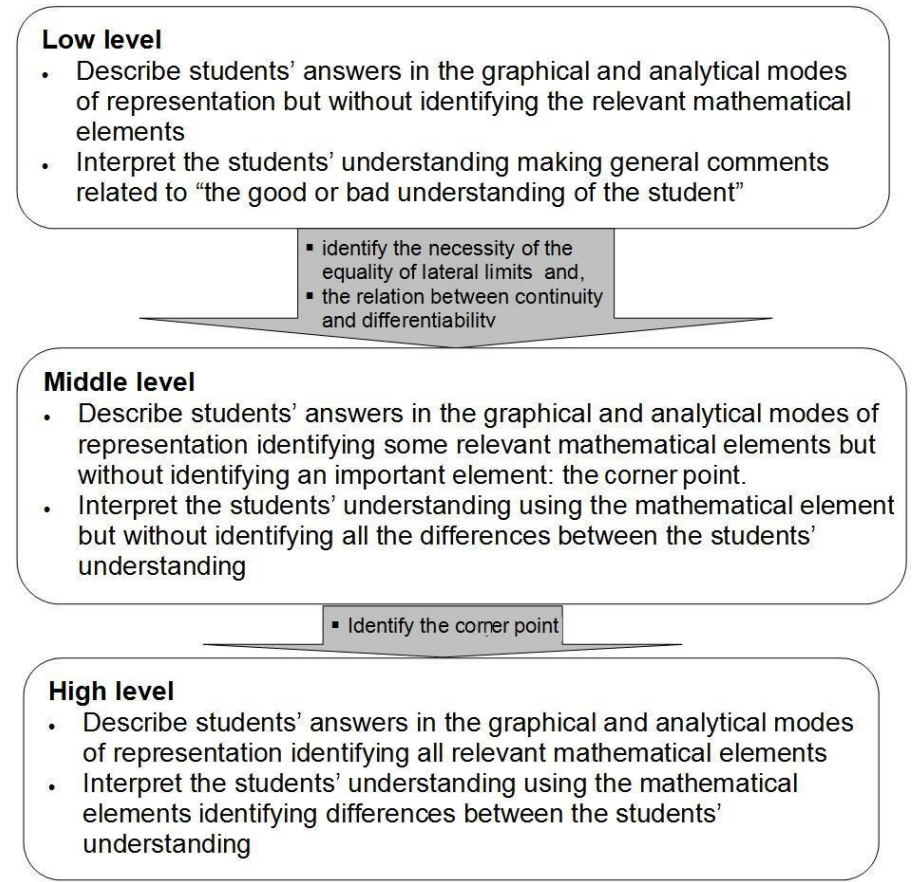

Figure 9. Development of the ability to notice students' understanding 
Upon completion of the teaching module, the PMTs who identified a larger number of mathematical elements in the students' answers were able to notice the signs of their understanding to a greater extent. This enabled six PMTs to identify the existence of different levels of understanding amongst the students when considering and comparing additional information from the students' written answers.

Furthermore, recognising the importance of the way in which students solve problems involving the corner point (final questionnaire, problem 2) can be interpreted as proof that mathematical knowledge is important in the development of the ability to notice students' understanding. This is due to the fact that, if the PMTs did not recognise the differences in the way in which the students set out to solve the problems involving the corner point, they were not able to recognise the different levels of development in the understanding of the derivative concept between students 2 and 3 .

In our teaching module, the process of comparing focused on two aspects. On the one hand, the subjects could compare the answers of a particular student to problems with different characteristics and, on the other; they could compare the answers of each problem from different students. Therefore, we suggest that the processes of Describing and Comparing enabled the PMTs to make more detailed assumptions about the students' understanding and to notice the different signs of understanding of the derivative concept. Thus, when the PMTs make an assumption, they are building a cognitive model about the students' understanding of the derivative and, therefore, increasing their knowledge of mathematics and that of their students (Ball et al., 2008). Jacobs et al. (2010) also emphasise the importance of identifying (attending to children's strategies) and interpreting (interpreting children's understanding) in order to be able to make informed decisions (deciding how to respond on the basis of children's understanding). The teachers' decisions are based on how the teacher notices the students' understanding. In this context, designing approaches based on error identification, 
analysing the reasons why these errors occur and designing approaches to correct and implement them helps teachers to understand the difficulties and challenges faced by their students (An \& Wu, 2012; Biza, Nardi \& Zhachariades, 2007).

\section{CONCLUSIONS}

The information from our research study contributes to the knowledge provided by other studies focusing on the topic of teachers learning to notice students' mathematical thinking. Our research study focuses on the characteristics of the changes in the way in which the PMTs notice the signs of students' understanding. These characteristics describe the changes in recognising and using the mathematical elements used by students to solve the problems. This information provides data to conjecture a developmental trajectory for acquiring this skill in the sense that our data showed different grades of the development of the skill of noticing after the teaching module. In addition, these results emphasise that the teaching module could help pre-service teachers to develop the ability to notice the signs of students' understanding. Thus, the design of the tasks which the PMTs were asked to carry out (reflected in the tasks of the questionnaires they completed before and after the teaching module) may have influenced the development of this skill.

From the results we obtained, we can conclude that explicitly recognising the mathematical elements used by students to solve problems and how they are linked with the modes of representation is one of the characteristics of a the development of the ability to notice students' understanding (Wilson et al., 2013). The idea of a trajectory for the skill of "noticing the signs of students' mathematical understanding" emphasises the development (between the pre and the post questionnaire) of the ability to interpret a student's work. This development can be understood as a continuous, increasingly sophisticated process in which noticing the signs of students' understanding is based on the detailed descriptions of the students' answers as a mean to making sense. 
Finally, we think that the description of the development, such as the one provided in this research study (figure 9), can be used by teacher trainers as a tool for designing training programmes for PMTs. Furthermore, the information regarding the development of this skill might provide means for assessing the development level of PMTs when teacher educators describe their progress in terms of levels of increasing sophistication.

ACKNOWLEDGEMENTS. This paper was supported by funding from the Ministry of Science and Innovation, Spain (EDU2011-27288) and Bird Project GRE10-10 from University of Alicante, Spain.

\section{References}

An, S. \& Wu, Z. (2012). Enhancing mathematics teachers' knowledge of students' thinking from assessing and analysis misconceptions in homework. International Journal of Science and Mathematics Education, 10, 717-753.

Artigue, M. (1990). Advanced mathematical thinking. In D. Tall (Ed.), Analysis (pp. 167198). Dordrecht: Kluwer Academic Publishers.

Asiala, M., Cottrill, J., Dubinsky, E. \& Schwingendorf, K. (1997). The development of students`graphical understanding of the derivate. Journal of Mathematical Behavior, $16,399-431$.

Baker, B., Cooley, L. \& Trigueros, M. (2000). A calculus graphing schema. The Journal for Research in Mathematics Education, 31, 557-578.

Ball, D. L., Thames, M. H. \& Phelps, G. (2008). Content knowledge for teaching: What makes it special? Journal of Teacher Education, 59, 389-407.

Bartell, T.G., Webel, C., Bowen, B. \& Dyson, N. (2013). Prospective teacher learning: recognizing evidence of conceptual understanding. Journal of Mathematics Teacher Education, 16, 57-79.

Badillo, E., Azcarate, C. \& Font, V. (2011). Análisis de los niveles de comprensión de los objetos $f^{\prime}(\mathrm{a})$ y $f^{\prime}(\mathrm{x})$ en profesores de Matemáticas. Enseñanza de las Ciencias, 29(2), 191-206. 
Biza, I., Christou, C., \& Zachariades, Th. (2008). Student perspectives on the relationship between a curve and its tangent in the transition from Euclidean Geometry to Analysis. Research in Mathematics Education, 10(1), 53-70.

Biza, I., Nardi, E. \& Zhachariades, Th. (2007). Using Tasks to Explñore Teacher Knowledge in Situation-Specific Contexts. Journal of Mathematics Teacher Education, 10, 301309.

Clements, D. \& Sarama, J. (2004). Learning trajectories in mathematics education. Mathematical Thinking and Learning, 6(2), 81-89.

Fernández, C., Llinares, S. \& Valls, J. (2012). Learning to notice students' mathematical thinking through on-line discussions. ZDM Mathematics Education, 44, 747-759.

Fernandez, C., Llinares, S. \& Valls, J. (2013). Primary school teacher's noticing of students' mathematical thinking in problem solving. The Mathematics Enthusiast, 10, 441-468.

Ferrini-Mundy, J. \& Graham, K. (1994). Research in calculus learning. Understanding limits, derivates and integrals. In J. Kaput \& E. Dubinsky (Eds.), Research issues in undergraduate mathematics learning, MAA notes 33 (pp. 31-45). Washington, DC: Mathematical Association of America.

Franke, M.L. \& Kazemi, E. (2001). Learning to teach mathematics: Focus on student thinking. Theory in practice, 40(2), 102-109.

García, M., Llinares, S. \& Sánchez-matamoros, G. (2011). Characterizing thematized derivative schema by the underlying emergent structures. International Journal of Science and Mathematics Education, 9, 1023-1045

Habre, S. \& Abboud, M. (2006). Student's conceptual understanding of a function and its derivative in an experimental calculus course. The Journal of Mathematical Behavior, $25,57-72$.

Jacobs, V.R., Franke, M.L., Carpenter, T.P., Levi, L. \& Battey, D. (2007). Professional development focused on children's algebraic reasoning in elementary School. Journal for Research in Mathematics Education, 38, 258-288.

Jacobs, V.R., Lamb, L.C. \& Philipp, R.A. (2010). Professional noticing of children's mathematical thinking. Journal for Research in Mathematics Education, 41, 169-202. 
Magiera, T.M., van den Kieboom, L.A. \& Moyer, J. (2013). An exploratory study of preservice middle school teachers' knowledge of algebraic thinking. Educational Studies in Mathematics, DOI 10.1007/s10649-013-9472-8

Mason, J. (2002). Researching your own practice. The discipline of noticing. London: Routledge Falmer.

Nagle, C., Moore-Russo, D., Viglietti, J. \& Martin, K. (2013). Calculus students' and instructors' conceptualizations of slope: A comparison across academic levels. International Journal of Science and Mathematics Education, 11(6), 1491-1515.

Sánchez-matamoros, G., García, M. \& Llinares, S. (2006). El desarrollo del esquema de derivada [The development of derivative schema]. Enseñanza de las Ciencias, 24(1), 85-98.

Sánchez-matamoros, G., García, M. \& Llinares, S. (2008). La comprensión de la derivada como objeto de investigación en Didáctica de la Matemática [The understanding of derivative as an research topic in Mathematics Education]. RELIME-Revista Latinoamericana de Investigación en Matemática Educativa, 11, 267-296.

Spitzer, S., Phelps, C.M., Beyers, J.E.R., Johnson, D.Y. \& Sieminski, E.M. (2011). Developing prospective elementary teachers' ability to identify evidence of student mathematical achievement. Journal of Mathematics Teacher Education, 14, 67-87.

Strauss, A. \& Corbin, J. (1994). Grounded theory methodology: An overview. In N.K. Denzin \& Y. Lincoln (Eds.), Handbook of qualitative research (pp. 273-285). Thousand Oaks: Sage.

van Es, E.A. \& Sherin, M.G. (2008). Mathematics teachers "learning to notice" in the context of a video club. Teaching and Teacher Education, 24, 244-276.

Wilson, P.H., Mojica, G.F. \& Confrey, J. (2013). Learning trajectories in teacher education: Supporting understandings of students' mathematical thinking. Journal of Mathematical Behavior, 32, 103-121.

Zandieth, M. (2000). A theoretical framework for analyzing student understanding of the concept of derivative. In E. Dubinsky, A.H. Shoenfeld \& J. Kaput (Eds.), Research in Collegiate Mathematics Education IV CBMS Issues in Mathematics Education (vol. 8, 103-127). Providence, USA: American Mathematical Society. 